\title{
MicroRNA-744 promotes carcinogenesis in osteosarcoma through targeting LATS2
}

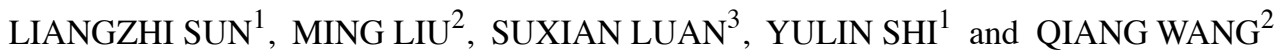 \\ ${ }^{1}$ Department of Orthopedics, Weifang People's Hospital, Weifang, Shandong 261041; \\ ${ }^{2}$ Department of Orthopedics, Hanting People's Hospital, Weifang, Shandong 261100; \\ ${ }^{3}$ Reproductive Medicine Centre, Weifang People's Hospital, Weifang, Shandong 261041, P.R. China
}

Received April 17, 2019; Accepted June 12, 2019

DOI: $10.3892 / \mathrm{ol} .2019 .10530$

\begin{abstract}
Osteosarcoma (OS) mortality rate is increasing. Various microRNAs (miRNAs) have been investigated in the pathological process of OS except for miR-744. Hence, this research was designed to explore miR-744 function in OS. RT-qPCR and western blot analysis were used to quantify miR-744 and large tumor suppressor kinase 2 (LATS2) expression levels. The function of miR-744 was investigated using MTT and Transwell assays. Target gene of miR-744 was verified by dual-luciferase reporter assay. miR-744 expression was increased in OS, which was associated with worse clinical features and prognosis of OS patients. Importantly, miR-744 promoted cell viability and metastasis in OS. Furthermore, miR-744 induced Wnt/ $\beta$-catenin pathway and epithelial-mesenchymal transition (EMT) in OS. In addition, miR-744 directly targeted LATS2 and blocked its expression in OS. Moreover, upregulation of LATS2 weakened the promotion of cell viability and metastasis induced by miR-744 in OS. In conclusion, miR-744 accelerated OS progression through restraining LATS 2 and activating $\mathrm{Wnt} / \beta$-catenin pathway and EMT.
\end{abstract}

\section{Introduction}

With the increasing incidence, osteosarcoma (OS) has become a major threat of human health. OS occurs mostly in childhood and adolescence. Approximately $80 \%$ of OS affect the growth of the femur and tibia (1). Previous studies have indicated that malignant transformation of OS cells is associated with genetic and environmental factors. The physiological dysfunction of OS cells is mainly caused by changes in oncogene and tumor suppressor activity (2). Moreover, OS cells are highly metastatic, including blood flow and lung metastasis. This

Correspondence to: Dr Suxian Luan, Reproductive Medicine Centre, Weifang People's Hospital, 151 Guangwen Street, Weifang, Shandong 261041, P.R. China

E-mail: obs3906400w@163.com

Key words: cell viability, metastasis, miR-744, osteosarcoma, LATS2 high degree of metastasis also leads to worse cure rate and prognosis in patients with OS (3). Despite the rapid development of modern diagnostic techniques, the complex pathological mechanisms of OS remain obstacles to patient survival (4). Therefore, further exploration of the pathogenesis of OS and the development of new treatments are of great significance for patients with OS.

MicroRNAs (miRNAs) are a class of evolutionarily conserved non-coding small RNAs that function to regulate gene expression at the translational level. The diversity and breadth of miRNAs have been revealed in many diseases and cancers in recent years, including OS. Zhou et al found the diagnostic effect of miR-139-5p as an indicator in OS (5). Additionally, miR-199b-5p was upregulated and promoted malignant progression of OS (6). Inversely, downregulation of miR-144 was found in OS. miR-144 overexpression inhibited tumor growth and metastasis in OS (7). Although many miRNAs have been found in OS, the dysregulation of miR-744 has not been investigated in OS. Moreover, the regulatory mechanism of miR-744 varies depending on the type of cancer. For instance, miR-744 was downregulated in glioblastoma and inhibited its aggressive behavior (8). On the contrary, miR-744 expression was increased in pancreatic cancer, which increased its tumorigenicity (9). Furthermore, miR-744 was a potential prognostic marker in patients with hepatocellular carcinoma (10). However, the molecular mechanism of miR-744 remains largely unknown in the pathological process of OS.

As a member of LATS tumor suppressor family, large tumor suppressor kinase 2 (LATS2) has been widely investigated in human cancers. For example, LATS2 was overexpressed in nasopharyngeal carcinoma and predicted poor prognosis (11). Functionally, LATS2, a putative tumor suppressor, inhibited G1/S transition (12). Furthermore, LATS2 was found to induce apoptosis by suppressing Bcl-2 expression (13). Dai et al found that LATS1/2 could inhibit f-actin binding, cell migration, and angiogenesis (14). The interaction between miRNAs and LATS2 had been investigated in some cancers. Lee et al reported that miR-373 post-transcriptionally regulated LATS2 and stimulated proliferation in human esophageal cancer (15). Moreover, miR-103 promoted metastasis and epithelial-mesenchymal transition (EMT) of hepatocellular carcinoma by inhibiting LATS2 (16). However, to the best of 
our knowledge, the relationship between miR-744 and LATS2 has not been previously investigated.

Therefore, the regulatory mechanism of miR-744/LATS2 axis was elucidated in our study. Furthermore, the effect of miR-744 on Wnt/ $\beta$-catenin pathway and EMT was also investigated in OS. This investigation will help us understand the pathogenesis of OS.

\section{Materials and methods}

Experimental sample. Forty-one OS patients in Weifang People's Hospital (Weifang, China) took part in this study. Informed consents of all OS patients were acquired before the experiment. OS tissues and normal tissues were acquired from these patients, who had not received any treatment except for surgery. Permission for this research was acquired from the Institutional Ethics Committee of Weifang People's Hospital.

Cell culture and transfection. Human normal osteoblast hFOB1.19 cells (ATCC ${ }^{\circledR}$ CRL-11372 ${ }^{\mathrm{TM}}$ ) and MG-63 OS cell line (ATCC ${ }^{\circledR} \mathrm{CRL}-1427^{\mathrm{TM}}$ ) were selected in this study. The growth conditions included $5 \% \mathrm{CO}_{2}, 37^{\circ} \mathrm{C}$ and culture solution (90\% RPMI-1640 + 10\% FBS). Next, miR-744 mimics, inhibitor, LATS2 siRNA and vector (RiboBio) were transfected into MG-63 cells, respectively, using Lipofectamine 2000.

$R T$ - $q P C R$. Total RNA extraction was performed by TRIzol reagent (Sigma-Aldrich; Merck KGaA). The cDNA solution was synthesized using First-Strand cDNA Synthesis kit (cat no. K1611; Promega Corporation). The temperature conditions of the reverse transcription were as follows: $37^{\circ} \mathrm{C}$ for $15 \mathrm{~min}$ and $85^{\circ} \mathrm{C}$ for $5 \mathrm{sec}$. We performed RT-qPCR assay using miScript SYBR ${ }^{\circledR}$-Green PCR kit (cat. no. /ID: 218073; Qiagen, Inc.) based on the manufacturer's instructions. The thermocycling parameters were as follows: $95^{\circ} \mathrm{C}$ for $3 \mathrm{~min}$ and 40 cycles of $95^{\circ} \mathrm{C}$ for $15 \mathrm{sec}$ followed by $58^{\circ} \mathrm{C}$ for $30 \mathrm{sec}$. The $2^{-\Delta \Delta \mathrm{Cq}}$ method (17) was applied to measure miR-744 or LATS2 expression levels using internal reference U6 or GAPDH. The following primers were used: miR-744 forward, 5'-ACACTCCAGCTGGGTGCGGGGCTAGGGCTAAC-3' and reverse, 5'-CTCAACTGGTGTCGTGGA-3'; LATS2 forward, 5'-ATGAGCTCCACTCTGCTCAATGTCACGG-3' and reverse, 5'-GCAAGCTTCTCTACCAAGAATGAAA GAGCAT-3'; U6 forward, 5'-CTCGCTTCGGCAGCACA-3' and reverse, 5'-AACGCTTCACGAATTTGCGT-3'; GAPDH forward, 5'-GAAGGTGAAGGTCGGAGTC-3' and reverse, 5'-GAGATGGTGATGGGATTTC-3'.

Western blot analysis. Transfected MG-63 cells were dissociated using RIPA lysis buffer. Next, 10\% SDS-PAGE was used to separate $25 \mu \mathrm{g}$ protein. Protein concentration was calculated using bicinchoninic acid (BCA). Protein samples were transferred into a polyvinylidene difluoride (PVDF) membrane (Thermo Fisher Scientifc, Inc.). Then, the membranes were blocked with 5\% non-fat milk for $1 \mathrm{~h}$ at room temperature. Protein samples were incubated with vimentin (rabbit polyclonal antibody; dilution, 1:1,000; cat. no. ab137321; Abcam), $\mathrm{N}$-cadherin (rabbit polyclonal antibody; dilution, 1:1,000; cat. no. ab18203; Abcam), E-cadherin (rabbit monoclonal antibody; dilution, 1:1,000; cat. no. ab1416; Abcam), LATS2 (rabbit polyclonal antibody; dilution, 1:1,000; cat. no. ab110780; Abcam), $\beta$-catenin (rabbit polyclonal antibody; dilution, 1:1,000; cat. no. ab6302; Abcam) and GAPDH (rabbit monoclonal primary antibody; dilution, 1:1,000; cat. no. ab181602; Abcam) overnight at $4^{\circ} \mathrm{C}$. Secondary mouse anti-rabbit (cat. no. 3678) or goat anti-mouse (cat. no. 58802) antibodies (dilution, 1:2,000) conjugated with horseradish peroxidase (Cell Signaling Technologies, Inc.) were added to incubate protein samples for $1 \mathrm{~h}$ at room temperature. Finally, ECL (ECL, Pierce) was used to measure protein expression levels.

MTT assay. The MG-63 cell suspension was cultured in RPMI-1640 medium containing 10\% FBS. Then, 96-well plates were seeded at a density of 4,000 cells per well. After $24,48,72$ and $96 \mathrm{~h}$ of incubation at $37^{\circ} \mathrm{C}, 20 \mu \mathrm{l}$ of MTT solution $(5 \mathrm{mg} / \mathrm{ml}$ in PBS) was added to each well. Incubation was continued for $4 \mathrm{~h}$ at $37^{\circ} \mathrm{C}$ and the culture was terminated. The supernatant was discarded, $150 \mu \mathrm{l}$ of DMSO was added to each well. The mixture was shaken for $10 \mathrm{~min}$ to allow the crystals to fully melt. Then, they were dissolved in $100 \mu \mathrm{l}$ of dimethyl sulfoxide [CAS: (67-68-5), Sangon Biotech]. Finally, at a wavelength of $490 \mathrm{~nm}$ the light absorption value of each well was measured on a microplate reader (ELx800; Bio-Tek Instruments) to plot a cell growth curve.

Transwell assay. First, $60 \mu \mathrm{l}$ of diluted Matrigel $(3.9 \mu \mathrm{g} / \mu \mathrm{l})$ was added to the upper chamber for cell invasion. Cell migration assay was performed without Matrigel. After $30 \mathrm{~min}$, MG-63 cell suspension $\left(5 \times 10^{3}\right.$ cells/well) was added to the Transwell upper chamber, and $500 \mu \mathrm{l}$ of RPMI-1640 medium (10\% FBS) was added to the 24-well plate in the lower chamber. After routine incubation for $24 \mathrm{~h}$, the cells on the lower surface of the membrane were fixed with $4 \%$ paraformaldehyde [CAS: (30525-89-4), Sangon Biotech] and stained with $1 \%$ crystal violet (Solarbio) for $5 \mathrm{~min}$. Observation and photographing were performed using a light microscope (Olympus Corporation).

Luciferase reporter assay. Luciferase vector pcDNA3.1 (Promega Corporation) with Wt-LATS2-3'UTR or Mut-LATS23'UTR and miR-744 mimics were transfected into MG-63 OS cell line (ATCC). Next, the transfected cells were incubated in RPMI-1640 medium (Gibco; Thermo Fisher Scientific, Inc.) at room temperature for $20 \mathrm{~min}$. After $48 \mathrm{~h}$, the medium was discarded and washed with PBS. Finally, luciferase activity was assessed using dual luciferase assay system (Promega Corporation). This experiment was repeated 3 times.

Statistical analysis. Data were analyzed by SPSS 18.0 (SPSS, Inc.) or GraphPad Prism 6 (GraphPad Software, Inc.), and shown as mean \pm SD. Chi-square test, one-way ANOVA with Tukey's multiple comparison tests and univariate Kaplan-Meier method with log-rank test were used to analyze differences between the groups. $\mathrm{P}<0.05$ was considered to indicate a statistically significant difference.

\section{Results}

miR-744 expression is increased in OS. The alteration of miR-744 expression was assessed in OS by RT-qPCR. We 
A

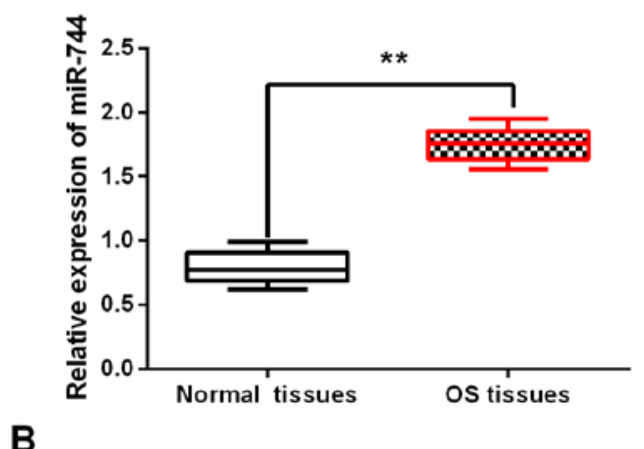

B

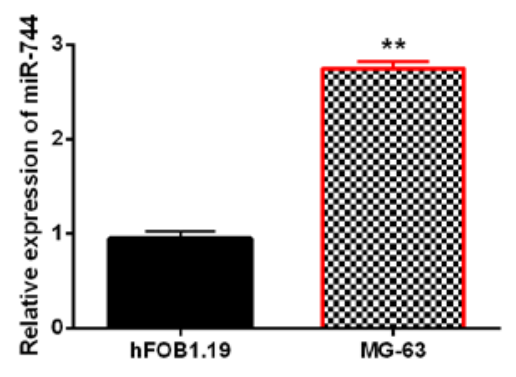

C

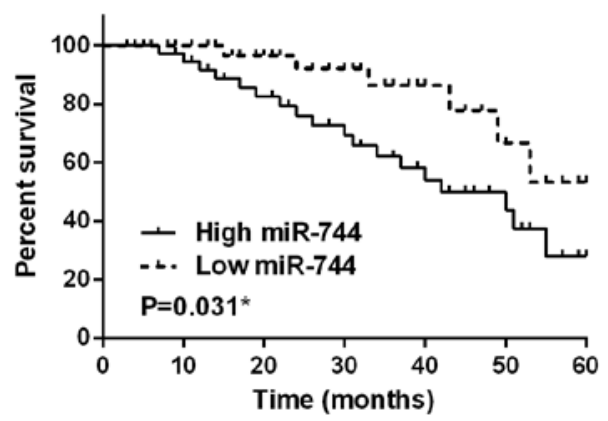

Figure 1. (A) Upregulation of miR-744 in OS. miR-744 expression levels in OS tissues. (B) miR-744 expression levels in MG-63 cells and hFOB1.19 cells. (C) High miR-744 expression was associated with unfavorable prognosis in OS patients. ${ }^{*} \mathrm{P}<0.05,{ }^{* *} \mathrm{P}<0.01$.

found that miR-744 expression was higher in OS tissues than in normal tissues $(\mathrm{P}<0.01$, Fig. 1A). Moreover, miR-744 was also upregulated in MG-63 cells compared to hFOB1.19 cells $(\mathrm{P}<0.01$, Fig. 1B). In addition, dysregulation of miR-744 affected the prognosis of OS patients. Upregulation of miR-744 was closely associated with worse prognosis in OS patients $(\mathrm{P}<0.05$, Fig. 1C). Besides, abnormal miR-744 expression was associated with distant metastasis and clinical stage $(\mathrm{P}<0.05$, Table I). These findings implied that miR-744 might influence OS progression.

miR-744 promotes cell viability and metastasis in OS. In order to confirm whether miR-744 was involved in OS development, gain-loss experiment of miR-744 was performed in MG-63 cells. After transfection, miR-744 expression was enhanced by its mimics and reduced by its inhibitor $(\mathrm{P}<0.01$, Fig. 2A). Next, miR-744 mimic overexpression was found to promote cell proliferation in OS. Correspondingly, knockdown of miR-744 inhibitor restrained MG-63 cell proliferation
Table I. Relationship between miR-744 expression and the clinicopathological characteristics of OS patients.

\begin{tabular}{lcccc}
\hline & & \multicolumn{2}{c}{ miR-744 } & \\
\cline { 3 - 3 } Characteristics & Cases & High & Low & P-value \\
\hline Age (years) & & & & 0.75 \\
$\geq 60$ & 25 & 18 & 7 & \\
$<60$ & 16 & 14 & 2 & \\
Sex & & & & 0.52 \\
Male & 24 & 19 & 5 & \\
Female & 17 & 13 & 4 & \\
Tumor size & & & & 0.12 \\
$<5$ cm & 20 & 13 & 7 & \\
$\geq 5$ cm & 21 & 19 & 2 & \\
Clinical stage & & & & $0.02^{\mathrm{a}}$ \\
I-II & 32 & 25 & 7 & \\
III-IV & 9 & 7 & 2 & \\
Distant metastasis & & & & $0.03^{\mathrm{a}}$ \\
No & 35 & 29 & 6 & \\
Yes & 6 & 3 & 3 & \\
\hline
\end{tabular}

Statistical analyses were performed by the $\chi^{2}$ test. ${ }^{\text {a }}<0.05$ was considered statistically significant.

( $\mathrm{P}<0.05$ or 0.01 , Fig. 2B). Consistently, cell migration was also promoted by miR-744 mimic overexpression and inhibited by downregulation of miR-744 inhibitor ( $\mathrm{P}<0.01$, Fig. $2 \mathrm{C}$ ). Similarly, miR-744 mimics promoted MG-63 cell invasion. miR-744 inhibitor restrained cell invasion in OS cells $(\mathrm{P}<0.01$, Fig. 2D). Hence, miR-744 played a carcinogenic role in OS development.

miR-744 induces Wnt/ $\beta$-catenin pathway and EMT in OS. Next, how miR-744 regulated Wnt/ $\beta$-catenin pathway and EMT was explored to confirm its effect on OS cell viability and metastasis. The expression levels of EMT makers (E-cadherin, $\mathrm{N}$-cadherin and vimentin) were measured in MG-63 cells with miR-744 mimics or inhibitor. We found that miR-744 mimics promoted $\mathrm{N}$-cadherin and vimentin expression levels and restrained E-cadherin expression in MG-63 cell (Fig. 3). Correspondingly, miR-744 inhibitor enhanced E-cadherin expression and blocked $\mathrm{N}$-cadherin and vimentin expression levels in OS cells (Fig. 3). In addition, we examined $\beta$-catenin expression as a regulator in Wnt/ $\beta$-catenin pathway in MG-63 cells with miR-744 mimics or inhibitor. The expression of $\beta$-catenin was promoted by miR-744 mimics and suppressed by miR-744 inhibitor (Fig. 3). These findings indicated that miR-744 promoted OS development through activating $\mathrm{Wnt} / \beta$ catenin pathway and EMT.

miR-744 negatively regulates LATS2 expression in OS. TargetScan database (http://www.targetscan.org/, Fig. 4A) showed that there were binding sites between LATS2 and miR-744 and the prediction was confirmed by luciferase reporter assay. miR-744 mimics lessened luciferase activities 

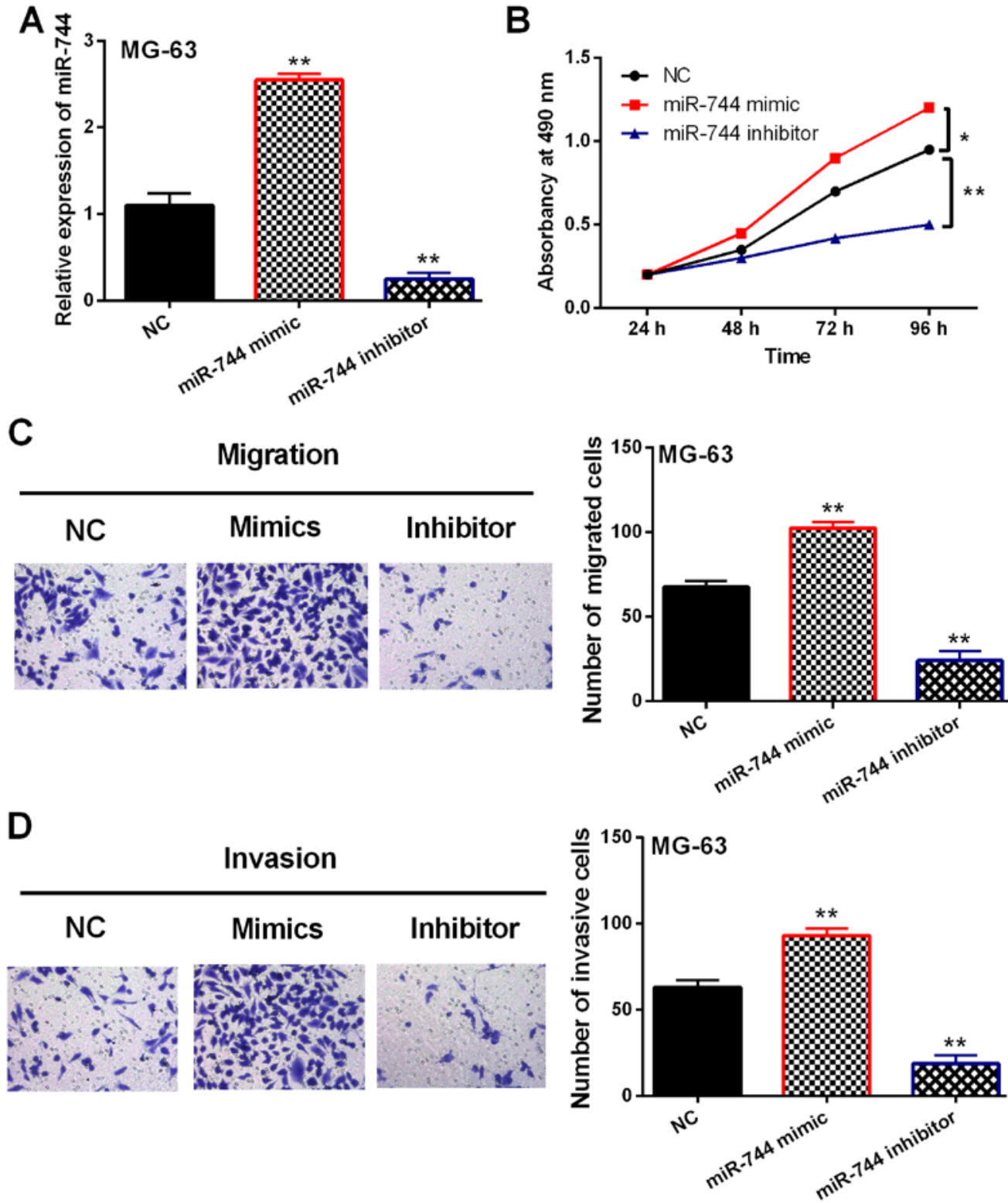

Figure 2. miR-744 promotes cell viability and metastasis in OS. (A) miR-744 expression in MG-63 cells with its mimics or inhibitor; (B-D) cell proliferation, migration and invasion were regulated by miR-744 in MG-63 cells. ${ }^{*} \mathrm{P}<0.05,{ }^{* *} \mathrm{P}<0.01$.

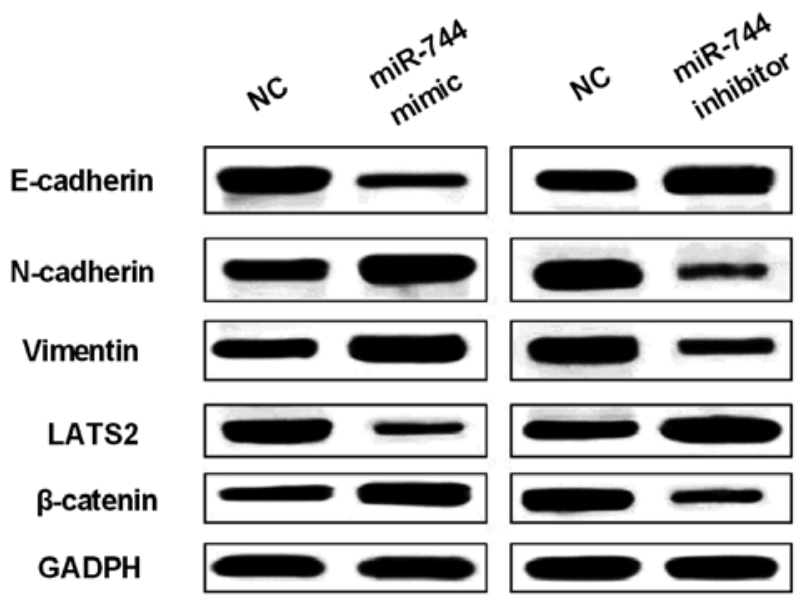

Figure 3. miR-744 induces EMT and Wnt/ $\beta$-catenin pathway in OS. EMT markers, LATS 2 and $\beta$-catenin were regulated by miR-744 mimics or inhibitor in MG-63 cells. of wild LATS2, but had no effect on mutant LATS2 $(\mathrm{P}<0.01$, Fig. 4B). LATS2 expression affected by miR-744 mimics or inhibitor was detected in MG-63 cells. LATS2 expression was found to be blocked by miR-744 mimics and increased by miR-744 inhibitor ( $\mathrm{P}<0.01$, Fig. 4C). Downregulation of LATS2 was found in OS tissues compared to normal tissues ( $\mathrm{P}<0.01$, Fig. 4D). Furthermore, miR-744 was found to have a negative association with LATS2 expression levels in OS tissues $\left(\mathrm{P}<0.0001, \mathrm{R}^{2}=0.4971\right.$; Fig. 4E). Based on these results, miR-744 directly targeted LATS2 and blocked its expression in OS.

miR-744 accelerates OS progression through targeting LATS2. Finally, MG-63 cells with miR-744 mimics were transfected with LATS2 vector to explore their interaction in OS. We found that miR-744 mimics mediated reduction of LATS2 expression which was recovered by LATS2 vector (Fig. 5A). Functionally, promotion of cell proliferation induced by 

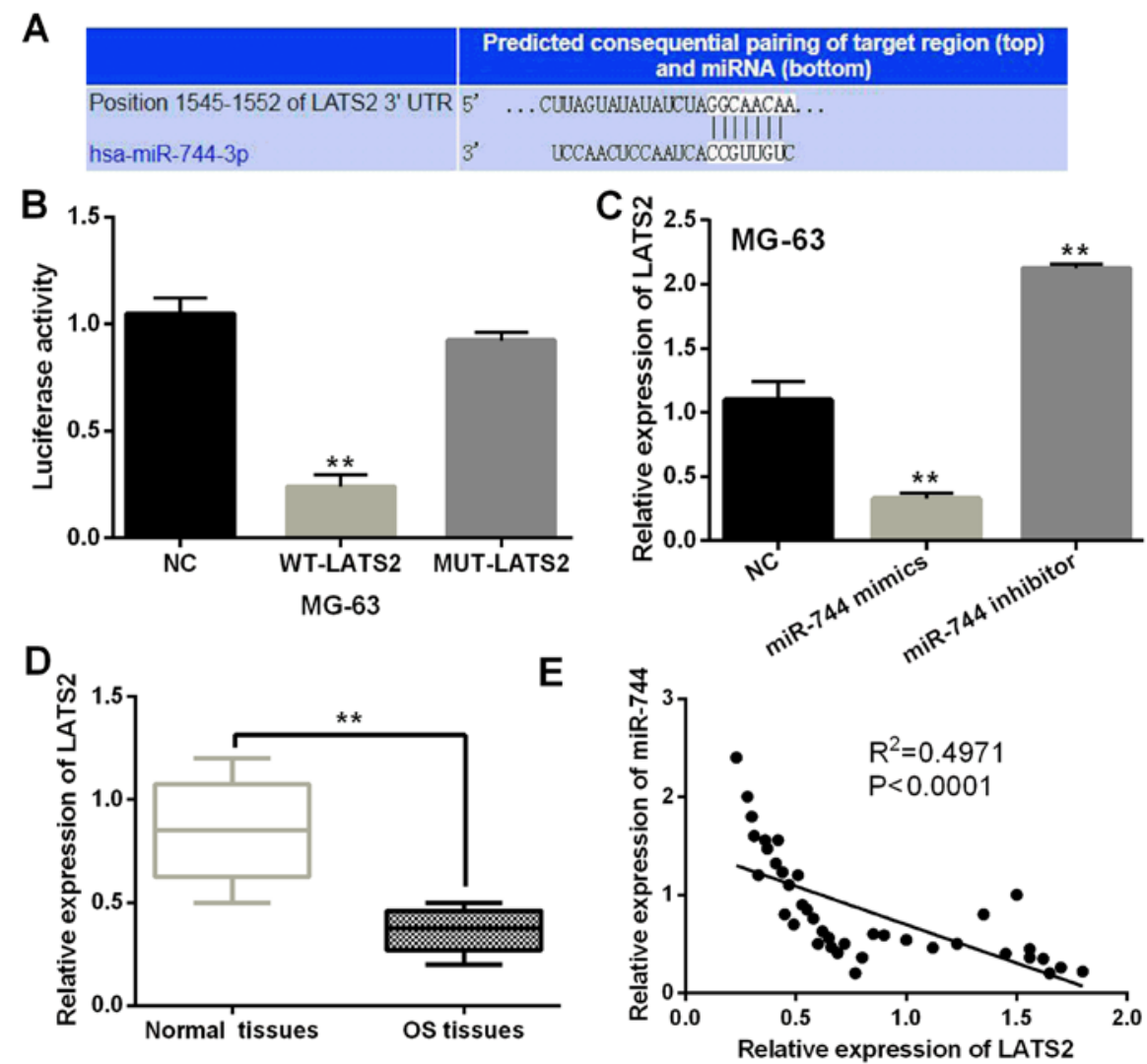

Figure 4. miR-744 negatively regulates LATS2 expression in OS. (A) The binding sites between miR-744 and LATS2. (B) Luciferase reporter assay. (C) LATS2 expression in MG-63 cells with miR-744 mimics or inhibitor. (D) LATS2 expression in OS tissues. (E) Negative association between miR-744 and LATS2. ${ }^{* * *} \mathrm{P}<0.01$.

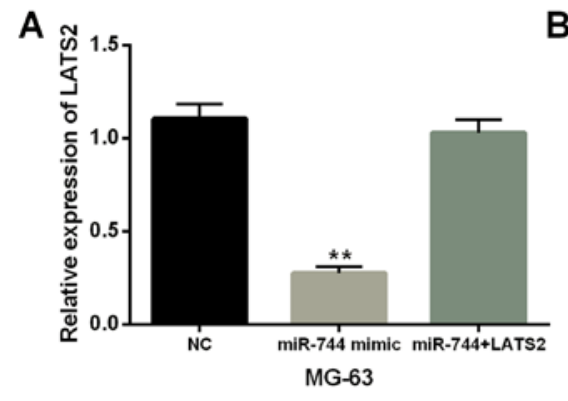

C
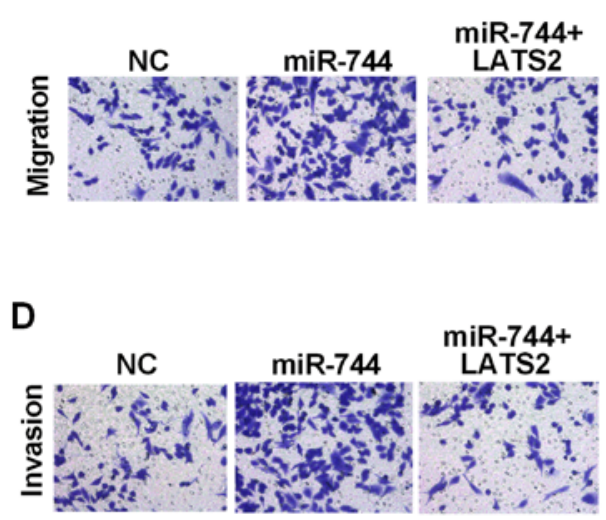

B
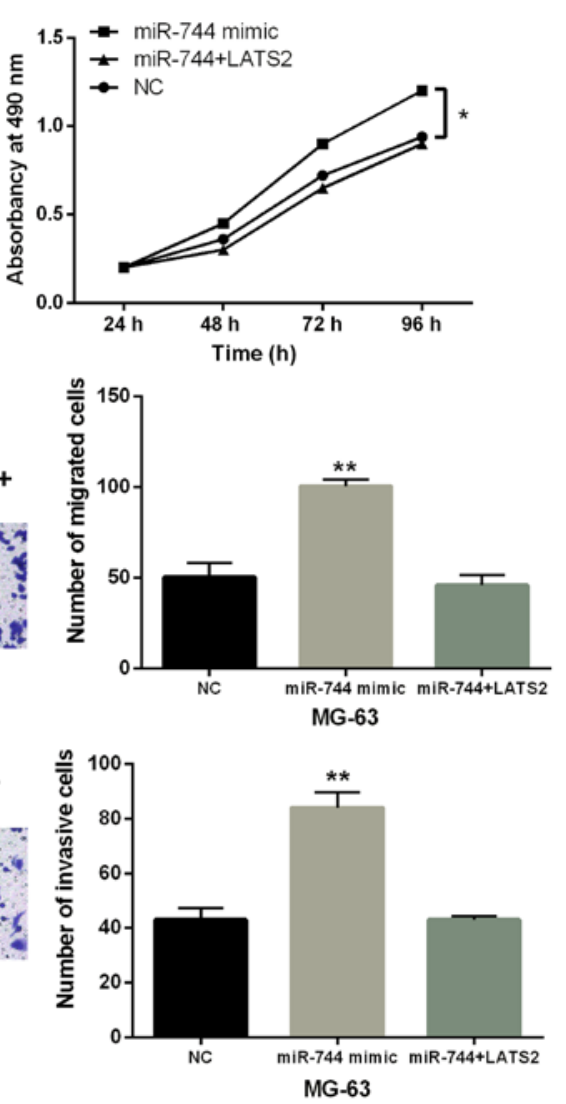

Figure 5. miR-744 accelerates OS progression via regulating LATS2. (A) LATS2 level in MG-63 cells containing miR-744 mimics and LATS2 vector. (B-D) Cell proliferation, migration and invasion in MG-63 cells with miR-744 mimics and LATS2 vector. ${ }^{*} \mathrm{P}<0.05,{ }^{* * *} \mathrm{P}<0.01$. 
miR-744 overexpression was impaired by upregulation of LATS2 (P<0.01, Fig. 5B). Similarly, promotion of cell migration and invasion regulated by miR-744 was also weakened by LATS2 upregulation ( $\mathrm{P}<0.01$, Fig. $5 \mathrm{C}$ and $\mathrm{D})$. Combining these results, miR-744 was considered to accelerate OS progression through targeting LATS2.

\section{Discussion}

As important regulators, miRNAs have been found to take part in the regulation of OS progress. Similarly to our results, miR-214 expression was increased in OS and promoted its malignant behavior (18). Li et al demonstrated that miR-374a activated $\mathrm{Wnt} / \beta$-catenin signaling to promote OS development (19). Here, upregulation of miR-744 was also measured in OS. Furthermore, this dysregulation was associated with worse clinical features and prognosis of OS patients. Functionally, promotion of OS cell proliferation, migration and invasion mediated by miR-744 was identified. Moreover, miR-744 activated Wnt/ $\beta$-catenin pathway and EMT to exhibit carcinogenesis in OS. Besides, we found that miR-744 accelerated OS progression through targeting LATS2. These findings implied that miR-744 acted as an oncogene in OS.

Consistent with our results, high expression of miR-744 was observed in nasopharyngeal carcinoma, which predicts poor prognosis (20). Moreover, similar results were also identified in pancreatic cancer (21). In addition, Li et al showed that miR-744 enhanced motility of SiHa cervical cancer cells (22), which agreed with our findings. At the same time, oncogenic miR-744 was found to promote prostate cancer growth (23). In our study, we also found miR-744 mediated promotion of cell viability in OS. It was reported that miR-744 promoted prostate cancer progression through aberrantly activating $\mathrm{Wnt} / \beta$-catenin signaling (24). Similarly, Wnt/ $\beta$-catenin pathway was also activated by miR-744 in OS, but the activation of EMT induced by miR-744 has not been investigated in previous studies. Previous studies have indicated that miR-744 carries out its functions by regulating the expression levels of its targets, such as KLLN and EEF1A2 $(25,26)$. Therefore, we investigated the interaction of LATS2 and miR-744 in this study. miR-744 was found to directly target LATS2 and block its expression in OS.

As a target gene, the expression of LATS2 is affected by other miRNAs in different cancers, such as miR-93 and miR-372 (27,28). As a tumor suppressor, dysregulation of LATS2 has been assessed in many malignant tumors. Downregulation of LATS2 was detected in colorectal cancer and esophageal squamous cell carcinoma (29,30). In the current study, LATS2 was also downregulated in OS. Furthermore, LATS2 had a negative association with miR-744 expression in OS tissues, which was consistent with previous studies. Functionally, miR-25 promoted ovarian cancer proliferation and motility by targeting LATS2 (31). Moreover, miR-650 promoted metastasis and EMT of hepatocellular carcinoma by inhibiting LATS2 expression (32). Here, miR-744 was also considered to facilitate cell proliferation and metastasis in OS through targeting LATS2.

Collectively, miR-744 expression was increased in OS, which predicted poor clinical features and prognosis. Moreover, miR-744 accelerated cell viability and metastasis in OS through downregulating LATS2. Furthermore, miR-744 activated Wnt/ $\beta$-catenin pathway and EMT to facilitate OS progression. Therefore, our study provides a new therapeutic target for OS patients.

\section{Acknowledgements}

Not applicable.

\section{Funding}

No funding was received.

\section{Availability of data and materials}

The datasets used and/or analyzed during the present study are available from the corresponding author on reasonable request.

\section{Authors' contributions}

LS contributed to the study design, data acquisition and analysis and drafted the manuscript. ML performed RT-qPCR and western blot analysis. SL and YS were responsible for MTT, Transwell and dual-luciferase reporter assays. QW contributed to analysis of observation indexes. All the authors read and approved the final manuscript.

\section{Ethics approval and consent to participate}

The study was approved by the Institutional Ethics Committee of Weifang People's Hospital (Weifang, China). Patients who participated in this research, had complete clinical data. Signed informed consents were obtained from the patients or the guardians.

\section{Patient consent for publication}

Not applicable.

\section{Competing interests}

The authors declare that they have no competing interests.

\section{References}

1. Clark JC, Dass CR and Choong PF: A review of clinical and molecular prognostic factors in osteosarcoma. J Cancer Res Clin Oncol 134: 281-297, 2008.

2. Geller DS and Gorlick R: Osteosarcoma: A review of diagnosis, management, and treatment strategies. Clin Adv Hematol Oncol 8: 705-718, 2010.

3. Cortini M, Avnet S and Baldini N: Mesenchymal stroma: Role in osteosarcoma progression. Cancer Lett 405: 90-99, 2017.

4. Tsiambas E, Fotiades PP, Sioka C, Kotrotsios D, Gkika E, Fotopoulos A, Mastronikolis SN, Armata IE, Giotakis E and Ragos V: Novel molecular and metabolic aspects in osteosarcoma. J BUON 22: 1595-1598, 2017.

5. Zhou L, Ma X, Yue J, Chen T, Wang XY, Wang ZW, Pan J and Lin Y: The diagnostic effect of serum miR-139-5p as an indicator in osteosarcoma. Cancer Biomark 23: 561-567, 2018.

6. Chen Z, Zhao G, Zhang Y, Ma Y, Ding Y and Xu N: MiR-199b-5p promotes malignant progression of osteosarcoma by regulating HER2. J BUON 23: 1816-1824, 2018.

7. Liu JL, Li J, Xu JJ, Xiao F, Cui PL, Qiao ZG, Chen XD, Tao WD and Zhang XL: MiR-144 inhibits tumor growth and metastasis in osteosarcoma via dual-suppressing RhoA/ROCK1 signaling pathway. Mol Pharmacol 95: 451-461, 2019. 
8. Deng Y, Li Y, Fang Q, Luo $\mathrm{H}$ and Zhu G: microRNA-744 is downregulated in glioblastoma and inhibits the aggressive behaviors by directly targeting NOB1. Am J Cancer Res 8: 2238-2253, 2018.

9. Zhou W, Li Y, Gou S, Xiong J, Wu H, Wang C, Yan H and Liu T: MiR-744 increases tumorigenicity of pancreatic cancer by activating Wnt/3-catenin pathway. Oncotarget 6: 37557-37569, 2015

10. Tan YL, Bai ZG, Zou WL, Ma XM, Wang TT, Guo W, Liu J, Li JS, Jie-Yin, Zang YJ, et al: miR-744 is a potential prognostic marker in patients with hepatocellular carcinoma. Clin Res Hepatol Gastroenterol 39: 359-365, 2015.

11. Zhang Y, Hu CF, Chen J, Yan LX, Zeng YX and Shao JY: LATS2 is de-methylated and overexpressed in nasopharyngeal carcinoma and predicts poor prognosis. BMC Cancer 10: 538, 2010.

12. Li Y, Pei J, Xia H, Ke H, Wang $\mathrm{H}$ and Tao W: Lats2, a putative tumor suppressor, inhibits G1/S transition. Oncogene 22: 4398-4405, 2003.

13. Ke H, Pei J, Ni Z, Xia H, Qi H, Woods T, Kelekar A and Tao W: Putative tumor suppressor Lats2 induces apoptosis through downregulation of Bcl-2 and Bcl-x(L). Exp Cell Res 298: 329-338, 2004

14. Dai X, She P, Chi F, Feng Y, Liu H, Jin D, Zhao Y, Guo X, Jiang D, Guan KL, et al: Phosphorylation of angiomotin by Lats $1 / 2$ kinases inhibits F-actin binding, cell migration, and angiogenesis. J Biol Chem 288: 34041-34051, 2013.

15. Lee KH, Goan YG, Hsiao M, Lee CH, Jian SH, Lin JT, Chen YL and Lu PJ: MicroRNA-373 (miR-373) post-transcriptionally regulates large tumor suppressor, homolog 2 (LATS2) and stimulates proliferation in human esophageal cancer. Exp Cell Res 315: 2529-2538, 2009.

16. Han LL, Yin XR and Zhang SQ: miR-103 promotes the metastasis and EMT of hepatocellular carcinoma by directly inhibiting LATS2. Int J Oncol 53: 2433-2444, 2018.

17. Livak KJ and Scmittgen TD: Analysis of relative gene expression data using real-time quantitative PCR and the 2(-Delta Delta C(T)) Method. Methods 25: 402-408, 2001.

18. Cai H, Miao M and Wang Z: miR-214-3p promotes the proliferation, migration and invasion of osteosarcoma cells by targeting CADM1. Oncol Lett 16: 2620-2628, 2018.

19. Li W, Meng Z, Zou T, Wang G, Su Y, Yao S and Sun X: MiR-374a activates $\mathrm{Wnt} / \beta$-catenin signaling to promote osteosarcoma cell migration by targeting WIF-1. Pathol Oncol Res: Dec 6, 2018 (Epub ahead of print)

20. Yu Q, Zhang F, Du Z and Xiang Y: Up-regulation of serum miR-744 predicts poor prognosis in patients with nasopharyngeal carcinoma. Int J Clin Exp Med 8: 13296-13302, 2015.

21. Miyamae M, Komatsu S, Ichikawa D, Kawaguchi T, Hirajima S, Okajima W, Ohashi T, Imamura T, Konishi H, Shiozaki A, et al: Plasma microRNA profiles: Identification of miR-744 as a novel diagnostic and prognostic biomarker in pancreatic cancer. $\mathrm{Br} J$ Cancer 113: 1467-1476, 2015
22. Li C, Jia L, Yu Y and Jin L: Lactic acid induced microRNA-744 enhances motility of SiHa cervical cancer cells through targeting ARHGAP5. Chem Biol Interact 298: 86-95, 2019.

23. Zhang M, Li H, Zhang Y and Li H: Oncogenic miR-744 promotes prostate cancer growth through direct targeting of LKB1. Oncol Lett 17: 2257-2265, 2019

24. Guan H, Liu C, Fang F, Huang Y, Tao T, Ling Z, You Z, Han X, Chen S, Xu B, et al: MicroRNA-744 promotes prostate cancer progression through aberrantly activating Wnt/ $\beta$-catenin signaling. Oncotarget 8: 14693-14707, 2017.

25. Wang C, Zong J, Li Y, Wang X, Du W and Li L: MiR-744-3p regulates keratinocyte proliferation and differentiation via targeting KLLN in psoriasis. Exp Dermatol 28: 283-291, 2019.

26. Vislovukh A, Kratassiouk G, Porto E, Gralievska N, Beldiman C, Pinna G, El'skaya A, Harel-Bellan A, Negrutskii B and Groisman I: Proto-oncogenic isoform A2 of eukaryotic translation elongation factor eEF1 is a target of miR-663 and miR-744. Br J Cancer 108: 2304-2311, 2013.

27. Fang L, Du WW, Yang W, Rutnam ZJ, Peng C, Li H, O'Malley YQ, Askeland RW, Sugg S, Liu M, et al: MiR-93 enhances angiogenesis and metastasis by targeting LATS2. Cell Cycle 11: 4352-4365, 2012

28. Cho WJ, Shin JM, Kim JS, Lee MR, Hong KS, Lee JH, Koo KH, Park JW and Kim KS: miR-372 regulates cell cycle and apoptosis of ags human gastric cancer cell line through direct regulation of LATS2. Mol Cells 28: 521-527, 2009.

29. Zheng YB, Xiao K, Xiao GC, Tong SL, Ding Y, Wang QS, Li SB and Hao ZN: MicroRNA-103 promotes tumor growth and metastasis in colorectal cancer by directly targeting LATS2. Oncol Lett 12: 2194-2200, 2016.

30. Gao Y, Yi J, Zhang K, Bai F, Feng B, Wang R, Chu X, Chen L and Song H: Downregulation of MiR-31 stimulates expression of LATS2 via the hippo pathway and promotes epithelial-mesenchymal transition in esophageal squamous cell carcinoma. J Exp Clin Cancer Res 36: 161, 2017.

31. Feng S, Pan W, Jin Y and Zheng J: MiR-25 promotes ovarian cancer proliferation and motility by targeting LATS2. Tumour Biol 35: 12339-12344, 2014.

32. Han LL, Yin XR and Zhang SQ: miR-650 promotes the metastasis and epithelial-mesenchymal transition of hepatocellular carcinoma by directly inhibiting LATS2 expression. Cell Physiol Biochem 51: 1179-1192, 2018.

This work is licensed under a Creative Commons Attribution-NonCommercial-NoDerivatives 4.0 International (CC BY-NC-ND 4.0) License. 